\title{
ACCESS TO VACCINATION IN THE GREATER POLAND (POLAND)
}

\author{
TOMASZ ZAPRUTKO', DOROTA KOPCIUCH', ANNA PACZKOWSKA', \\ DOMINIKA SAWICKA ${ }^{2}$, ZUZANNA STACHOWIAK ${ }^{2}$, PATRYCJA BOGDANIEC ${ }^{2}$, \\ KRZYSZTOF KUS ${ }^{1}$ and ELŻBIETA NOWAKOWSKA ${ }^{1}$
}

\begin{abstract}
${ }^{1}$ Department of Pharmacoeconomics and Social Pharmacy, Poznan University of Medical Sciences, 7 Rokietnicka Street, 60-806 Poznań, Poland

${ }^{2}$ Student Scientific Society, Department of Pharmacoeconomics and Social Pharmacy, Poznan University of Medical Sciences, 7 Rokietnicka Street, 60-806 Poznań, Poland

Abstract: Immunization is a very effective health intervention. Moreover, the global vaccines market has been growing rapidly and costs of full children immunization are dramatically higher nowadays than they were 30 years ago. High vaccine prices may limit affordability of vaccination which is why we attempted an evaluation of availability and affordability of 7 and non-reimbursed vaccines mostly used in children in Poland. The study was conducted between October 2016 and October 2017 using a specially designed anonymous questionnaire comprising three closed-ended questions. The study tool was distributed by direct contact or via the Internet. Eventually, answers from 505 pharmacies from the Greater Poland region and 10 primary care clinics were included. 5 out of 7 vaccines were available in all types of facilities. There were some issues, however, with availability of Bexsero ${ }^{\circledR}$ and Nimenrix ${ }^{\circledR}$. Considering prices, the highest difference (of more than $100 \%$ ) was found for Infanrix hexa ${ }^{\circledR}$ and the lowest (38.5\%), for Infanrix IPV+HIB ${ }^{\circledR}$. In $88.17 \%$ of pharmacies included, patients were informed about a thermo-insulating package. $48.39 \%$ of respondents indicated that such package is free of charge, while in other pharmacies an average price for the package was EUR 0.48. Although availability and affordability of medicines are crucial objectives of the public health policy, it seems that access to vaccines in Poland might be an area for improvement. Thus, prices of non-reimbursed vaccines could be regulated in Poland nationwide. Moreover, to provide trustworthy information concerning vaccination, healthcare decision makers should consider social education about immunization as an important issue.
\end{abstract}

Keywords: access, vaccines, pharmacies, pharmaceutical market, Poland

Immunization is known to be one of the most effective health interventions (1) and vaccines are being considered some of the greatest achievements of medicine in the struggle against numerous infectious diseases (2). In addition to this, vaccination has had an indisputable impact on global health not only in the world's poorest countries (3) but also in the richest ones such as the United States (US), for instance, where routine childhood vaccination has kept most vaccine-preventable diseases at the lowest levels ever (4).

Considering vaccination as a preventive strategy, it is important to point out that the economic burden of full immunization of children has grown significantly over the last decades (4). It might be related to the increasing sophistication of vaccines including pneumococcal or rotavirus vaccination and popularization of combined vaccines likewise (5). However, the use of polyvalent vaccines, which include several antigens in a single administration, gives multiple potential benefits. Aside from the reduction in the frequency of visits and possible complications related to multiple intramuscular injections, combined vaccines decrease the costs of administering and stocking separate vaccines as well as costs of the patient's caregivers who in case of monovalent vaccines might have to get a childcare leave repeatedly and be absent from work (5).

In spite of the fact that immunization demonstrates efficacy $(2,6)$, remains one of the most costeffective preventive strategies (4), and is related to the United Nations' Millennium Goals such as reduction of child mortality and improvement of maternal health (3), access to vaccines might be restricted by their high prices $(6,7)$. It results, among other things, from the fact that the development of new vaccines is a long and expensive process (3). Nonetheless, vaccination is indicated as

\footnotetext{
* Corresponding author: e-mail: tomekzaprutko@ump.edu.pl
} 
crucial for public health (3) and the importance of access to medicines at affordable prices is emphasized both by the European Commission and the US Department of Health and Human Services $(8,9)$. Therefore, on the one hand, affordability of medicines, including vaccines, should be a key goal for healthcare decision makers $(7,10,11)$ but, on the other, about one-third of the global population is still unable to obtain essential medicines mainly due to the price barrier $(8,12)$. Hence, we attempted an evaluation of availability and affordability of 7 nonreimbursed vaccines mostly used in children. We have also decided to consider market competition which may affect access to the study vaccines and their affordability, especially due to potential differences in drug prices even within one country $(7,10$, 13-15).

\section{Material and methods}

The study was conducted between October 2016 and October 2017 using a specially designed anonymous questionnaire comprising three closedended questions. Participation in the study was voluntary. We considered 7 non-reimbursed vaccines (Table 1). The use of brand names is strongly limited to avoid any accusations of advertising, even though sometimes these names are presented.

In question 1, participants were to answer which vaccine is available in their pharmacy and what is such medicine's price. In question 2 , respondents were to indicate if there was a possibility to order a currently unavailable vaccine and what was the waiting time. In question 3, however, study participants were to choose whether a thermo-insulating package was available free of charge upon purchase of a vaccine or whether there was an extra charge for it. If an extra charge was checked, participants were to indicate the amount of such a fee. The questionnaire is available upon request from the corresponding author.

The study tool was delivered (by direct contact and by e-mail) to pharmacists from the Greater Poland region which is the third largest region in Poland in terms of population, with approximately 3.5 million inhabitants. Moreover, Greater Poland covers almost $10 \%$ of the surface of Poland and is comparable to the area of such countries as Belgium or Armenia.

Over 700 questionnaires were distributed and participants were requested to answer at once or to return the questionnaire by e-mail or by regular mail at a later date. Potential study participants were selected from the list of pharmacies in the Greater Poland (according to information from the Central Statistical Office at the end of 2016, there were 13,104 regular pharmacies in Poland, of which 1,299 pharmacies in the Greater Poland). Eventually, answers concerning 505 pharmacies were included in the study. 198 pharmacies were excluded from the study, of which 107 because of the pharmacists' refusal to join the project, especially due to the terms of their contract which did not

Table 1. The list of analyzed vaccines and their clinical particulars.

\begin{tabular}{|c|c|}
\hline Brand name & Clinical particulars \\
\hline Bexsero $^{\circledR}$ & $\begin{array}{l}\text { The meningitis B vaccine is indicated for active immunization of individuals from } \\
2 \text { months of age and older against invasive meningococcal disease caused by } \\
\text { Neisseria meningitidis group B. }\end{array}$ \\
\hline $\begin{array}{l}\text { Infanrix- } \\
\text { IPV+Hib }^{\circledR}\end{array}$ & $\begin{array}{l}\text { Vaccine against diphtheria, tetanus, pertussis, poliomyelitis and Haemophilus influenzae } \\
\text { type b disease from the age of } 2 \text { months. }\end{array}$ \\
\hline Infanrix hexa ${ }^{\circledR}$ & $\begin{array}{l}\text { Vaccine is indicated for primary and booster vaccination of infants and toddlers against } \\
\text { diphtheria, tetanus, pertussis, hepatitis } \mathrm{B} \text {, poliomyelitis and disease caused } \\
\text { by Haemophilus influenzae type b. }\end{array}$ \\
\hline Rotarix $^{\circledR}$ & $\begin{array}{l}\text { Vaccine is indicated for the active immunization of infants aged } 6 \text { to } 24 \text { weeks } \\
\text { for prevention of gastro-enteritis due to rotavirus infection. }\end{array}$ \\
\hline Varilrix $^{\circledR}$ & $\begin{array}{l}\text { Vaccine is indicated for active immunization against varicella of healthy } \\
\text { subjects (from the age of } 9 \text { months). }\end{array}$ \\
\hline Prevenar $13^{\circledast}$ & $\begin{array}{l}\text { Vaccine is indicated for active immunization for the prevention of } \\
\text { invasive disease, pneumonia and acute otitis media caused by Streptococcus pneumoniae } \\
\text { in infants (from } 6 \text { weeks), children and adolescents (to } 17 \text { years of age). }\end{array}$ \\
\hline Nimenrix $^{\circledR}$ & $\begin{array}{c}\text { Vaccine is indicated for active immunization of individuals from the age of } \\
6 \text { weeks against invasive meningococcal diseases caused by Neisseria meningitidis } \\
\text { group A, C, W-135, and Y. }\end{array}$ \\
\hline
\end{tabular}

Source: www.medicines.org.uk (16) 
allow them to disclose data about drug prices and 91 due to the lack of any reply. Importantly, where there was no reply received, the request to fill in the questionnaire was reiterated twice.

In terms of types of pharmacies in Poland (independent and chain stores), those included were divided into 4 groups. The first group named "independent" (IN) applied to answers received from a business organization consisting of only 1 pharmacy. The second one, however, was named "microchain" (MC) with 2 to 5 stores in the business organization. The third one and the last one, called "chain" (CH) and "big chain" (BC) applied to a business organization with 6 to 15 pharmacies or with more than 15 pharmacies respectively.

To make the study more interesting, responses obtained from the pharmacies were compared to those provided by 10 primary care clinics (PCC) where vaccines were available for purchase. 15 PCCs refused to join the study without specifying the grounds for their decision. Due to the no need for vaccine transportation, the respondents from PCCs were not asked about the thermo-insulating package. Money values obtained in Polish zloty (PLN) were converted to EUR based on the average EUR exchange rate published by the National Bank of Poland on October 31, 2017 (EUR $1=$ PLN 4.25). Money values presented in the study are a rounding of the amounts calculated in the currency conversion.

\section{RESULTS}

In the study, IN pharmacies constituted $41.49 \%$, MC pharmacies $-25.53 \%$, $\mathrm{CH}$ pharmacies $-18.09 \%$, and BC pharmacies $-14.89 \%$. Overall, 5 out of 7 analyzed vaccines were available in all types of pharmacies. Bexsero ${ }^{\circledR}$, however, was not available offhand at any of the studied IN pharmacies while Nimenrix ${ }^{\circledR}$ was available on the spot only at BC pharmacies. Importantly, none of the study vaccines was available in all of the pharmacies included. Nevertheless, considering convenient access to vaccines and their availability, it is essential to point out that although a vaccine might not have been attainable in selected pharmacies, there was quite frequently possibility of ordering it from internal stock in chain pharmacies, making the vaccine available on the same or the next day.

Despite the fact that study participants quite frequently indicated that vaccine was out of stock in wholesale warehouses, the respondents generally claimed that vaccines might be delivered to their pharmacy within 2 or 3 business days. Study participants claimed that it resulted from their contracts and/or cooperation with pharmaceutical companies' sales representatives. Pharmacists hardly ever indicated that they had to wait more than 7 business days for medicine delivery. Nonetheless, in case of Bexsero $^{\circledR}$ as well as of Infanrix IPV+HIB ${ }^{\circledR}$, almost $50 \%$ and $70 \%$ of respondents, respectively (Table 2 ), indicated that they were unable to order these vaccines and, therefore, to provide them to their patients.

In terms of prices, there were significant differences in prices of the study vaccines (Table 2) between pharmacies, exceeding $100 \%$ in the case of Infanrix hexa ${ }^{\circledast}$. The lowest difference, on the other hand, was noted for Infanrix IPV $+\mathrm{HIB}^{\circledR}$ and amounted to $38.5 \%$. Although thermo-insulating package seems to be indispensable in proper transportation of vaccines (each of the study vaccines needs to be stored in a fridge), only $88.17 \%$ of the study pharmacies informed their customers about such packages. $48.39 \%$ of respondents indicated that thermo-insulating package was free of charge upon vaccine purchase at their pharmacy. At other pharmacies, however, the patients had to pay an extra charge for the thermo-insulating bag. The lowest price was EUR 0.12 at an IN pharmacy. The highest, on the other hand, was EUR 0.94 and was reported for an MC pharmacy. Average price for the thermoinsulating package was EUR 0.48.

In the case of vaccine prices at PCCs, the lowest offer saved some money (in PLN) compared to drugstores prices. Thus, it might seemingly be stated that prices of vaccines at PCCs were close to those observed at the pharmacies (Table 2). Nonetheless, there are some important advantages of access to vaccines at PCCs, such as no need for a thermo-insulating package or better control of vaccine storage. On the other hand, however, distances between PCCs included were very long making patients unlikely to be willing to travel between cities and/or villages to get a cheaper medicine as it would not bring them any profit.

\section{DISCUSSION}

Access to medicines is considered a primary human right (10). Therefore, immunization as a very effective strategy both from the medical and economical point of view $(1,2,4)$ should be available for everyone. Moreover, availability and affordability of life-saving vaccines is one of the three main recommendations of the Global Vaccine Action Plan aimed at closing the immunization gap (1).

Although Poland is a high-income country (17), observed price variations of the analyzed vac- 


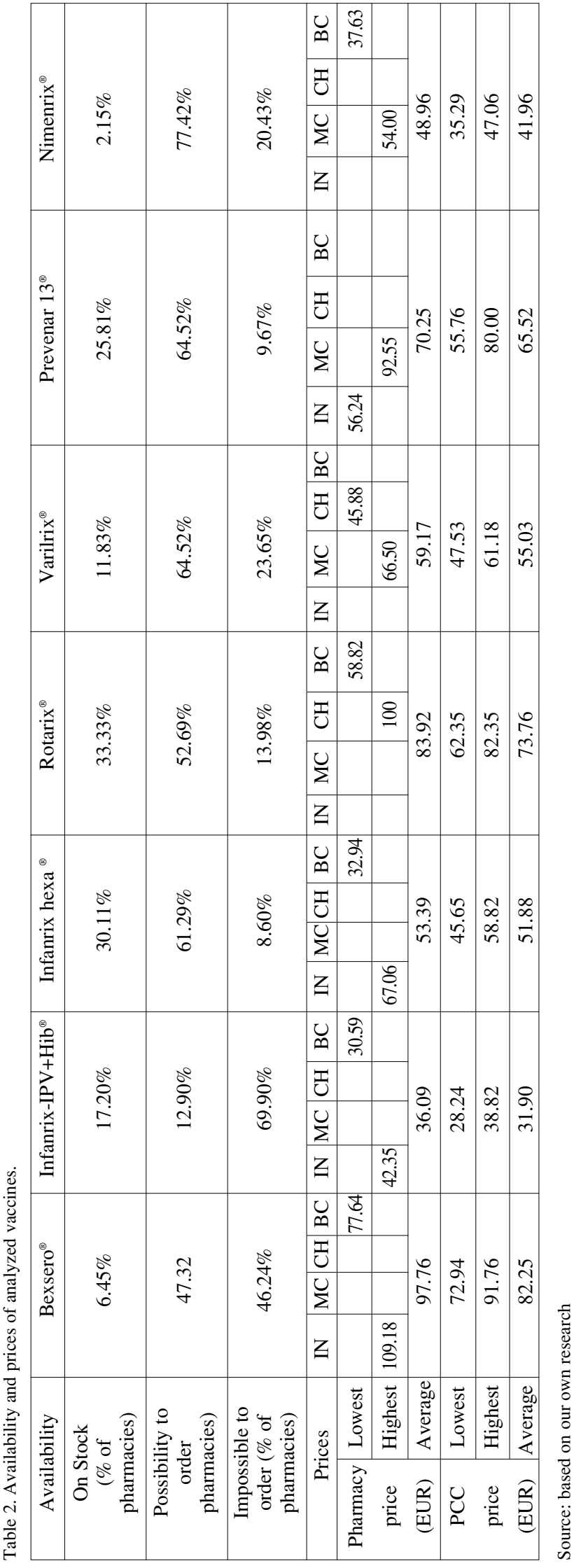

cines may contribute to the unaffordability of these medicines, making the patients give up vaccination entirely or use vaccines selectively. Moreover, our results generally corroborated with other studies where authors indicated significant differences in drug prices which could jeopardize public health $(7,10,13,18)$.

Taking into consideration changes in vaccine recommendations, the global vaccines market has been growing by approximately $8 \%$ annually and is expected to reach USD 84.5 billion by 2022 (2). Moreover, the cost of a complete noninfluenza vaccine set for children aged 018 increased from USD 260 in the 1990s to about USD 1630 in 2014 which constituted $12.5 \%$ of annual growth rate (4). This seems to confirm the crucial role of vaccination but also emphasizes the importance of unrestricted access to vaccines which should be priced adequately to the local economy. It is important because lower to middle-income countries receive rather small external support for their vaccination programs while these countries represent about $57 \%$ of the annual global birth rate (19). This might be due to, among other things, many years of delay in the introduction of vaccines in low-income countries compared to industrialized ones (3). Nevertheless, some vaccines might be required only in poor areas, and, due to the lack of a clear return on investment for pharmaceutical companies from such locations, the development and provision of an actual access to immunization is a huge challenge for manufacturers (3). Thus, the supply of vaccines to low-income countries might be considered one of the main reasons for high vaccine prices in developed countries. It could be also recognized as something similar to "free riding" which stems from the belief that poor countries have cheap medicines because they do not pay for research and development, while these costs are covered by richer countries $(7,20)$. Price discrepancies observed in this study show, however, that vaccine prices could be optimized even in high-income countries, leading to a better affordability.

Our findings showed that every vaccine analyzed was characterized by price 
differences as well as some problems with its availability (Table 2). For rotavirus vaccine, the price ranged from EUR 65.88 (EUR 62.35 at the cheapest PCC) to EUR 100 at the most expensive pharmacy. Despite this for the vast majority of patients it would be impossible or unprofitable (according to data from Central Statistical Office in Poland the minimum gross salary as of January 1, 2018 is EUR 494.12 and average gross salary according to data registered at the end of 2017 is EUR 1084.89) to cover many kilometers within the Greater Poland to get a cheaper vaccine. The discrepancies presented confirm that lower prices of vaccines are possible and could contribute to the cost-effectiveness of vaccination in richer countries. This statement is in line with conclusions presented by Aidelsburger et al. (6) who claimed that cost-saving scenarios could be implemented in Germany if the rotavirus vaccine price was reduced by about $65 \%$. On the other hand, however, in the study by Muangchana et al. (21), rotavirus vaccine was recognized as cost-effective in poorer countries. It was also confirmed by Patel et al. (22) who concluded that rotavirus vaccination program was predicted to reduce health and economic burden of rotavirus gastroenteritis in Pakistan by approximately $40 \%$.

In spite of the fact that vaccines can prevent infections and hospitalizations $(2,6,23)$, health-care decision makers should think how to reduce the economic burden of vaccination. Our findings showed that vaccines were generally cheaper at all types of chain pharmacies than at independent ones. This finding is in line with a study conducted by Gellad et al. (24). Price differences between chain and independent pharmacies may result from different possibilities of price negotiations. If chain pharmacies buy e.g. 100 packages of vaccine, they are clearly able to negotiate better offer than an independent pharmacy which is interested in single boxes. Thus, different negotiating power may contribute to the impaired access to vaccines at the study pharmacies. The main reason for such view may be referred to market consciousness. Pharmacies who know in advance that the price they are offered is significantly higher than the retail price at some chain pharmacies may give up purchasing of such medicine entirely in order to avoid stigmatization as an expensive place. Furthermore, chain pharmacies might be more commercially oriented, making them reduce their profit margins on products which could be deemed opinion-forming goods. Moreover, chain pharmacies as suggested by Gellad et al. (24) might be better perceived owing to the possible common pricing ensuring same price for the medicine (including vaccines) anywhere throughout the chain. The lowest prices of the study vaccines, however, were offered at PCCs which were independent entities. This is contrary to possible reasons for price differences between independent and chain drugstores and their chances to negotiate different prices. Nevertheless, it might be significantly easier to get a better price at a PCC because sales representatives of pharmaceutical companies may decide to generate a better PR and make an "investment" in the relationship between such company and a physician. Anyway, such suppositions and vaccine prices recorded at PCCs seem to confirm the need for solutions which would contribute to common access to vaccines at lower prices.

Although the new Reimbursement Act passed in Poland in 2012 "reinforced" the position of the Polish pharmaceutical market as one of the cheapest in the EU (25), affordability of vaccines remained questionable. On the one hand, the Reimbursement Act made prices of reimbursed medicines rigid and fixed by the Ministry of Health but, on the other, if a medicine is not on this list - its price can be freely established. Importantly, most Member States control pharmaceutical prices for reimbursable medicines but only 5 EU countries regulate prices of all medicines (26). Thus, it could be crucial to add the study vaccines onto the Polish reimbursement list or even to introduce a nationwide price regulation to allow governmental experts negotiate common prices.

Apart from the price barrier, possible resignation from vaccination might result from misconceptions about immunization (27). Among several antivaccine beliefs, some of them seem to be dangerous and are related to adverse side effects or even patient's death (27). It could be understandable that unaware parents are afraid for their children when they hear such misconceptions, frequently presented in mass media. Hence it is important to provide proper education about vaccines and their efficacy $(2,3,11,27)$ to give the parents accurate information instead of browbeating them into vaccinating their children (27). Moreover, people should be advised of suitable transportation of vaccines, especially when they travel from pharmacy to pharmacy (due to limited financial resources) to buy a cheaper vaccine. Besides, the thermo-insulating package protects the vaccine for a limited time only and, as presented herein, requires an extra charge at many pharmacies. Therefore, it seems that regulated and common prices of vaccines as well as providing the thermo-insulating package as an integral part of vaccine purchase might reduce the risks related to inap- 
propriate transportation of vaccines. It would also ensure a more convenient access to immunization without the need to keep searching for the vaccine at a better price.

As found in our study, access to vaccines was not impaired at PCCs, prices were competitive to those offered at drugstores, and there was no transportation problem. Therefore, it could be interesting to support the purchase of vaccines at PCCs. It might be also convenient because patients do not need to get a prescription from their PCC and come back with a vaccine bought at a pharmacy. However, pharmacists would be clearly very mistrustful of such a concept as it would naturally make them lose the market share. Hence healthcare decision makers could stipulate that vaccine price would be, for instance, EUR 5 more expensive at a PCC than at a pharmacy. If someone would rather save time than money, they may decide to get the medicine directly from their PCC. Polish healthcare decision makers should work, however, not only to ensure unlimited access to vaccines at affordable prices but also to provide effective education of patients in order to dispel some common misconceptions (27) about immunization.

Our study has some limitations, though. It would, therefore, be interesting to carry out the study across the country. Nevertheless, the problem seems to be common throughout Poland and the presented results were convergent within the Greater Poland region and might, hence, be considered representative. We are also aware that it could be valuable to include more PCCs in the study. Inclusion of more vaccines (e.g. vaccine against hepatitis B) would add value to such analysis. Last but not least, further research is necessary to extend the study onto a larger sample and to update conclusions, thus it could be interesting to extend the study onto other European countries and then to incorporate economic factors into the analysis (e.g. Gini coefficient, GDP per capita, PPP).

\section{CONCLUSION}

Despite the fact that several committees identified affordability and availability of medicines as crucial goals of the public health policy, it seems that access to the study medicines is still impaired due to significant price differences of vaccines offered in Poland, and may require improvement. Thus, it seems that price regulations should be stipulated for this specific group of medicines and nationwide negotiations should support achievement of lowest market prices both within areas with higher and lower market competition. Potential decisions should be aimed at providing equal and affordable access to medicines as well as social education about immunization to eliminate common misconceptions about the issue.

\section{Acknowledgments}

We would like to give our thanks to everyone who disinterestedly took their time to help us collect the data.

\section{Fund}

The study was supported by a grant (502-1403316440-10596) from the Poznan University of Medical Sciences, Poland. The funders had no role in study design, data collection and analysis, decision to publish, or preparation of the manuscript.

\section{Conflict of interest}

None declared.

\section{Ethical approval}

Not required, because, this article does not contain any studies with human participants performed by any of the authors.

\section{REFERENCES}

1. Muhammad U.K.: Lancet 17, 136 (2017).

2. Jadhav S., Gautam M., Gairola S.: Clin. Microbiol. Infect. 20, 37 (2014).

3. MacLennan CA.: Semin. Immunol. 25, 114 (2013).

4. Chen W., Messonnier M., Zhou F.: Vaccine 34, 4706 (2016).

5. Esposito S., Tagliabue C., Bosis S., Ierardi V., Gambino M., Principi N.: Clin. Microbiol. Infect. 20, 76 (2014).

6. Aidelsburger P., Grabein K., Böhm K., Dietl M., Wasem J. et al.: Vaccine 32, 1964 (2014).

7. Zaprutko T., Kopciuch D., Kus K., Merks P., Nowicka M. et al.: PlosOne 12, e0172753 (2017).

8. European Commission. High Level Group on Health Services and Medical Care. Surrey: European Commission (2004).

9. Cleemput I., Franken M., Koopmanschap M., le Polain M.: Int. J. Technol. Assess. Health Care 28, 358 (2012).

10. Vogler S., Kilpatrick K., Babar Z.: Value Health 18, 484 (2015). 
11. Saokaew S., Rayanakorn A., Wu D.B., Chaiyakunapruk N.: Pharmacoeconomics 34, 1211 (2016).

12. Kanavos P., Vandoros S., Irwin R., Nicod E., Cassod M.: European Parliament's Committee on Environment. Brussels, Belgium: European Parliament (2011).

13. Wagner J.L., McCarthy E.: Annu. Rev. Public Health 25, 475 (2004).

14. Schulenburg F., Vandoros S., Kanavos P.: Health Econ. Rev. 1, 18 (2011).

15. Gellad W.F., Choudhry N.K., Friedberg M.W., Brookhart MA, Haas J.S., Shrank W.H.: Health Serv. Res. 44, 606 (2009).

16. www.medicines.org.uk (accessed 19 December 2017).

17. https://datahelpdesk.worldbank.org/knowledgebase/articles/906519\#High_income (accessed 03 January 2018).

18. Cameron A., Ewen M., Ross-Degnan D., Ball D., Laing R.: Lancet 373, 240 (2009).
19. Makinen M., Kaddar M., Molldrem V., Wilson W.: Health Policy Plan. 27, 39 (2012).

20. Light D.W., Lexchin J.: BMJ 331, 958 (2005).

21. Muangchana C., Riewpaiboon A., Jamsiri S., Thamapornpilas P., Warinsatian P.: Vaccine 30, 2839 (2012).

22. Patel H.D., Roberts E.T., Constenla D.O.: Vaccine 31, 6072 (2013).

23. Alderson M.R.: Vaccine 34, 2959 (2016).

24. Gellad W.F., Choudhry N.K., Friedberg M.W., Brookhart M.A., Haas J.S., Shrank W.H.: Health Serv. Res. 44, 606 (2009).

25. Gloor C., Dantes M., Graefenhain E., Pantazis A., Poole J. et al.: Birgli Report. Zug, Switzerland (2013).

26. Vogler S., Habl C., Bogut M., Voncina L.: Croat. Med. J. 52, 183 (2011).

27. http://www.who.int/vaccine safety/initiative/ detection/immunization misconceptions/en/ (accessed 03 January 2017).

Received: 06.09. 2018 